\title{
Growth-Metropolitan vs. Nonmetropolitan Areas in the Central Mississippi Valley
}

Is 算 $\mathrm{N}$ POPULAR LITERATURE there is a tendency to emphasize the growth of metropolitan areas and to overlook developments in smaller cities, towns, and unincorporated, urban-type communities. Numerous publications have pointed to the rapid migration to large centers and the adjustment problems which accompany growth. ${ }^{1}$

Several basic national trends have probably contributed to the emphasis on metropolitan areas. The number of people living in metropolitan areas rose from 94 million in 1950 to 132 million in 1966. In contrast, the population in the farm sector dropped sharply. The number of people living on farms declined from 23 million to 10 million, and the farm portion of total population declined from 15 per cent to 5 per cent. This large How of people from farm to city has intensified problems of transportation, air pollution, crime, housing, and education. Because of the great interest in these problems and their association with larger cities, it is often assumed that metropolitan areas are growing more rapidly than other sectors."

In contrast to the above assumption, this article indicates that metropolitan areas in the Central Mississippi Valley (CMV) states (that is, Arkansas, Kentucky, Mississippi, Missouri, and Tennessee) have not been growing faster than nonfarm communities outside metropolitan areas. Smaller cities, towns and urban-type communities in this region (excluding the farm sector) have been growing at substantially faster rates than the large centers, according to such measures of economic activity as population, employment, and wage payments. Furthermore, total bank deposits and per capita personal income have been growing faster in nonmetropolitan areas (including the farm sector) than in the metropolitan centers.

\footnotetext{
1 For example, see: William H. Whyte, Jr., et. al., The Exploding Metropolis (New York: Doubleday and Company, Inc., 1958), p. 138 and Robert $H$. Connery (ed.), ${ }^{4}$ U Riots: Violence and Social Change," Proceedings of the Academy of Political Science, (New York: Columbia University, 1968), p. 161 .

2See Alvin C. Winston, "An Urbanization Pattern for the United States," Land Economics, February, 1967 , pp. 1.9. And Luther Gulich, "The Financial Plight of the Cities," Cutrent History, December, 1968, pp. 333-340.
}

\section{Central Mississippi Valley Trends}

Several measures of economic activity are used in this article to compare growth patterns in metropolitan and nonmetropolitan areas of each CMV state. The metropolitan portion of a state is defined here as all counties included in any metropolitan area as of 1967, even though in earlier years some of the counties may have been classified differently. Metropolitan Kentucky, for example, is defined as Jefferson County in the Louisville Standard Metropolitan Statistical Area (SMSA), Boyd County in the Huntington-Ashland SMSA, Boone, Campbell and Kenton Counties in the Cincinnati SMSA, Henderson County in the Evansville SMSA, and Fayette County in the Lexington SMSA. The remainder of the state is designated as nonmetropolitan."

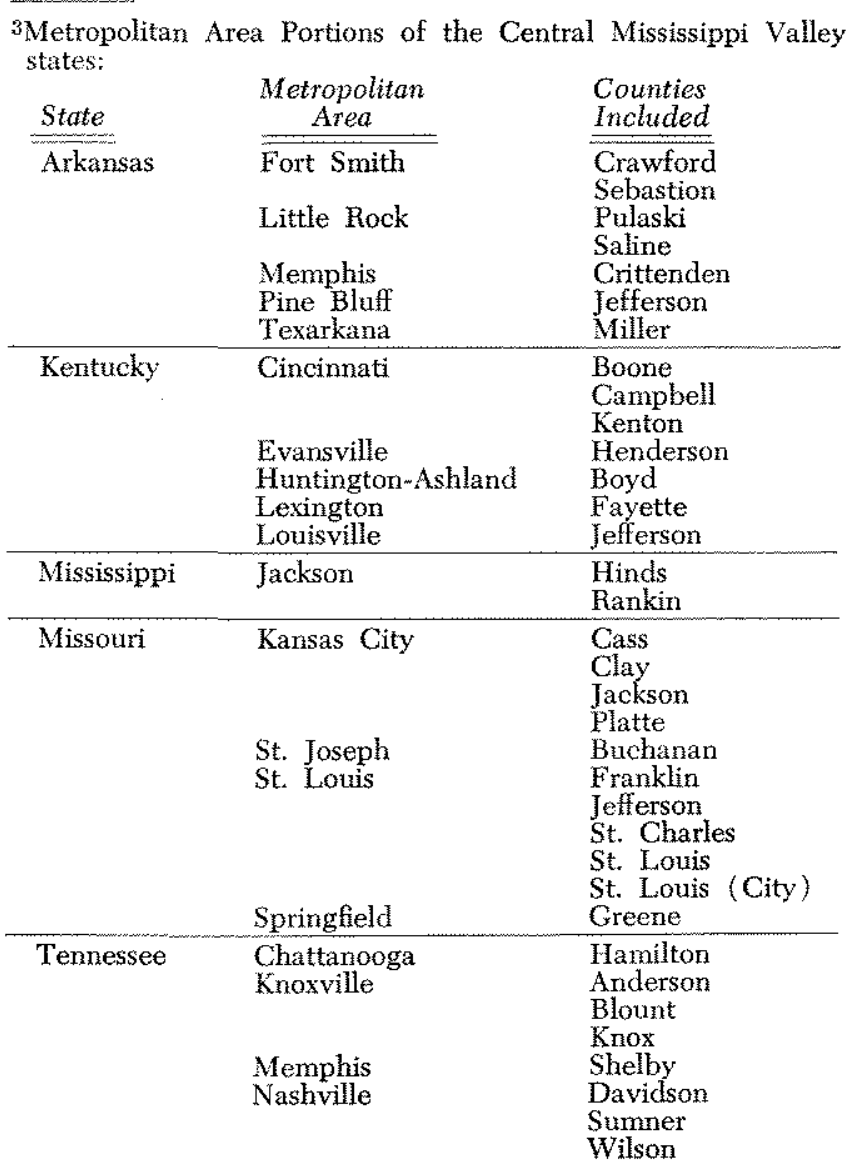


The time period used for most of the analyses is from the 1957-59 average to the latest year for which data are available. There is some deviation from the base period when data for 1957-59 could not be obtained or when a longer period appeared more appropriate. Economic growth measures considered include population, employment, wages, bank deposits and per capita income.

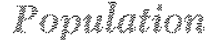

Major relocations of the population occurred in the Central Mississippi Valley from 1950 to 1966 . The change reflects a mass movement from the farm to the nonfarm sector (Table I). Population in both metropolitan areas and smaller communities increased faster as a result of this shift. Gains in nonfarm population outside of metropolitan areas, however, were at greater rates than in metropolitan areas.

The farm population in the Central Mississippi Valley declined at a 5.7 per cent annual rate from 1950 to 1966 , somewhat faster than in the nation. The decline was most rapid in the southern portion of the region. Lower per capita farm incomes and a relatively high ratio of farm to total population probably contributed to the rapid decline. Only Missouri, with

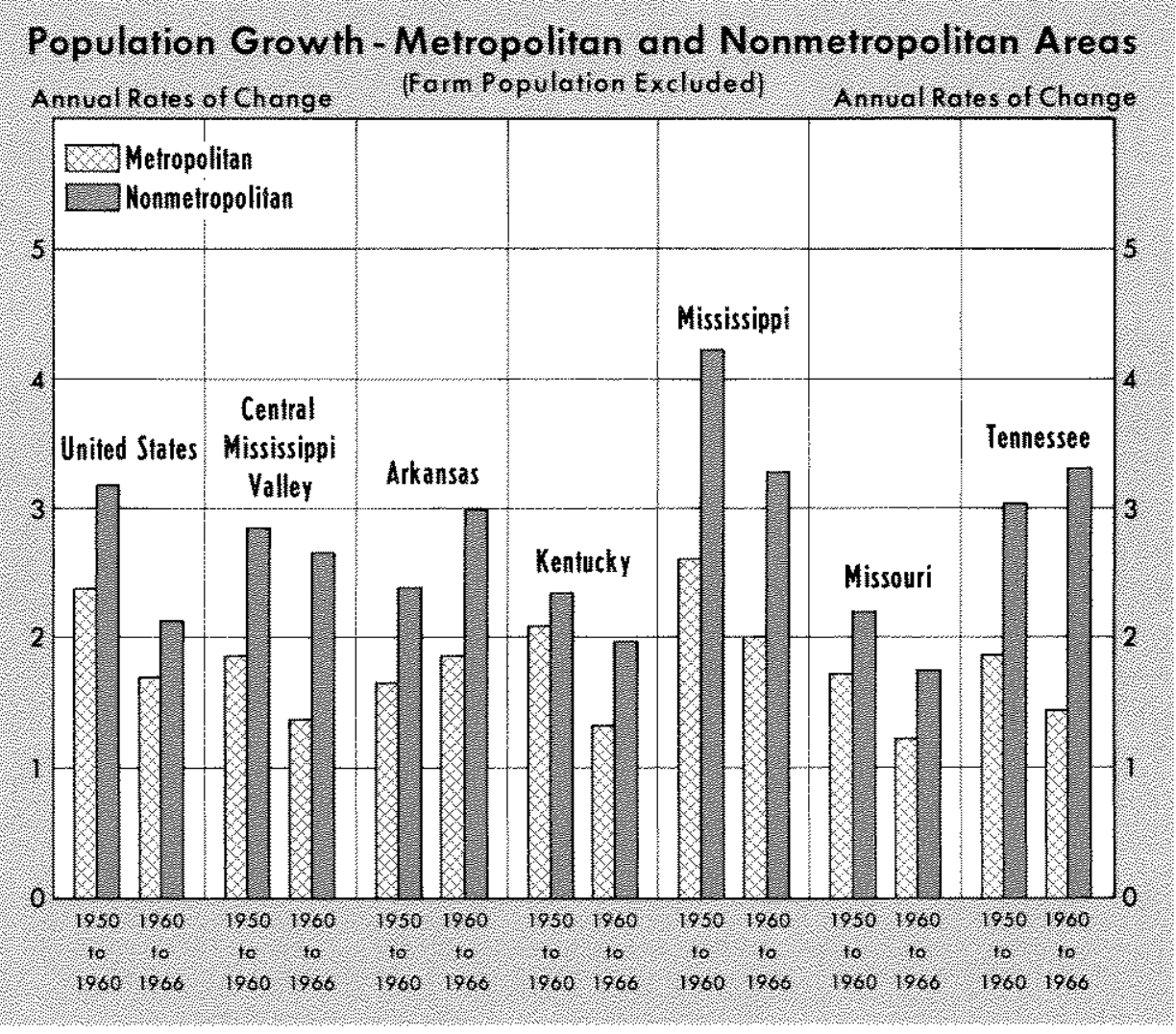

a per capita farm income of $\$ 865$, exceeded the national average, and this was the only state in which the farm population declined at a lower rate than the national average. The rate of decline in the other four states ranged from 7.1 per cent in Arkansas to 5.3 per cent in Kentucky and Tennessee; the comparable national rate was 4.9 per cent. In 1950 per capita farm income in the four southern states of the region ranged from $\$ 364$ in Tennessee to $\$ 547$ in Arkansas,

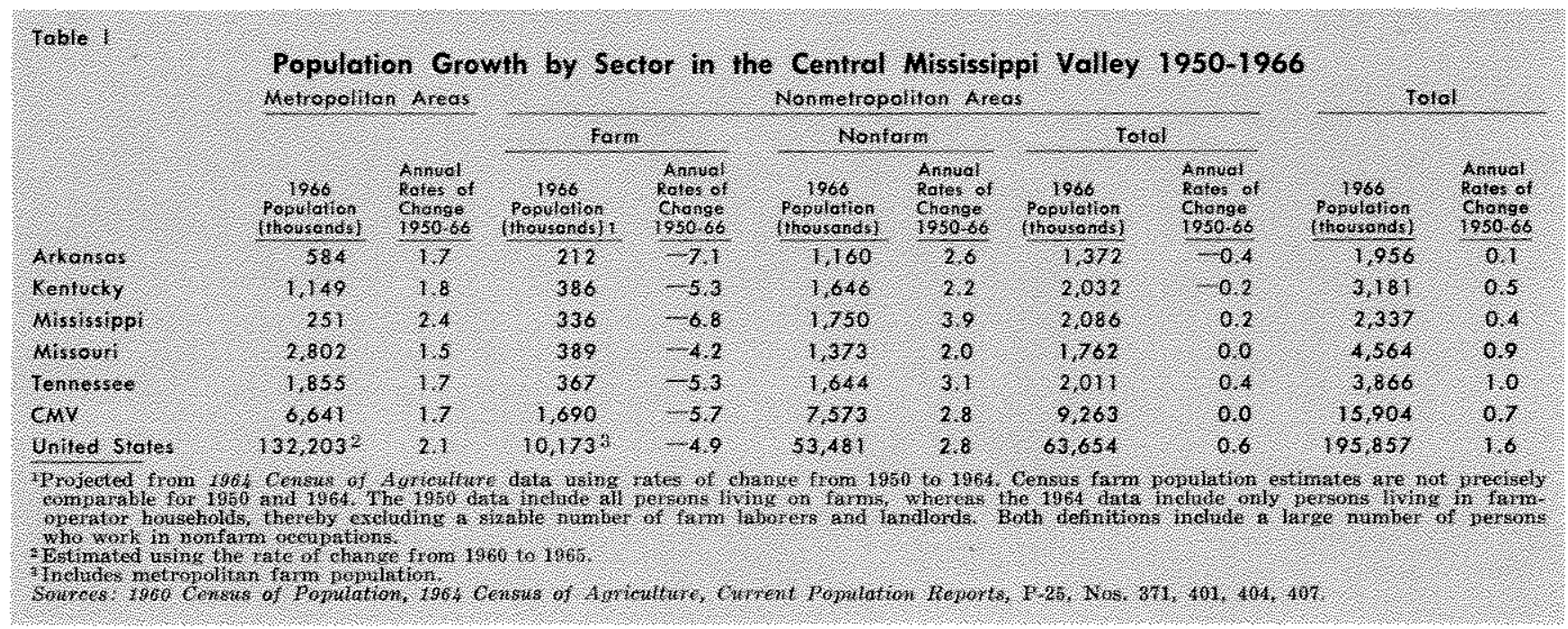


compared with a national average per capita farm income of $\$ 736$.

Population living on fams in Mississippi declined from 49 per cent to 14 per cent of the total, while in Arkansas, farm population declined from 37 per cent to 11 per cent of the total population during the 16 year period. In comparison, the number of people living on farms in Missouri declined from 20 per cent to 9 per cent. In the United States the decline was from 15 per cent to 5 per cent.

Despite the sharp decline of the farm population in the Central Mississippi Valley, metropolitan areas in the region grew somewhat more slowly than the national average. The average metropolitan area growth rate for all CMV states was 1.7 per cent, compared with 2.1 per cent in the nation. Metrom politan area population grew fastest in the states with the smallest metropolitan concentration. Mississippi, which has 11 per cent of its population living in metropolitan areas, had an annual metropolitan population growth rate of 2.4 per cent from 1950 to 1966 . On the other hand, metropolitan Tennessee, with 48 per cent of the state's population, had a growth rate of 1.7 per cent, and metropolitan Missouri, with 61 per cent of the population, advanced at a 1.5 per cent rate.

The nonfarm population outside metropolitan areas, the largest sector in all regional states except Missouri and Tennessee, was the most rapidly growing population sector in the Central Mississippi Valley from 1950 to 1966 . This sector advanced at a 2.8 per cent rate, equal to the national rate of growth for these communities.

\section{Employment}

Employment trends in the CMV states paralleled those of population. Based on data for workers covered by state employment security laws (about half of all workers), the employment growth rate in nonmetropolitan areas exceeded that in metropolitan areas in each of the five Valley states from 1957-59 to 1967.

Nonmetropolitan employment growth in the region ranged from 5.3 per cent per year in Kentucky to 3.8 per cent in Mississippi (Table II). Again, a stateby-state analysis of total covered employment indiated generally higher growth rates in the southern portion of the Valley, where the ratio of farm to nonfarm population was highest, and the shift from farm to nonfarm employment was greatest.

In Arkansas total covered employment expanded at a 4.7 per cent rate in nonmetropolitan areas compared with 3.9 per cent in metropolitan centers. The rapid. expansion of manufacturing employment in the nonmetropolitan counties largely accounts for this growth differential. Manufacturing employment growth in these areas is probably related to the in-migration of labor-intensive industries to take advantage of lower wage rates. Nonmanufacturing employment increased at about the same rate in the metropolitan and nonmetropolitan sectors.

Manufacturing employment growth in Kentucky nonmetropolitan areas far outpaced that in metropolitan areas. Such employment, which accounts for about one-fourth of the state total, expanded at a 5.3 per cent rate in nonmetropolitan areas compared with a 2.2 per cent rate in metropolitan areas. This is a reversal of the growth pattern prior to about 1960. Since then, however, manufacturing employ

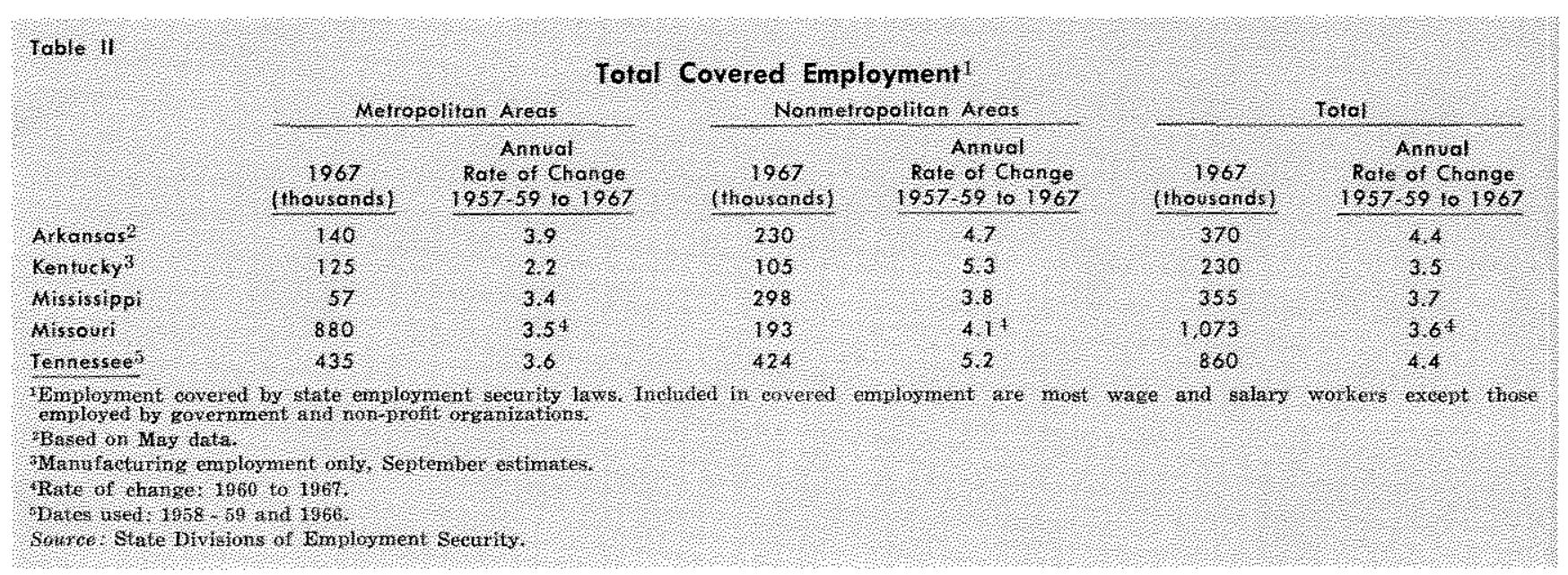

Page 10 


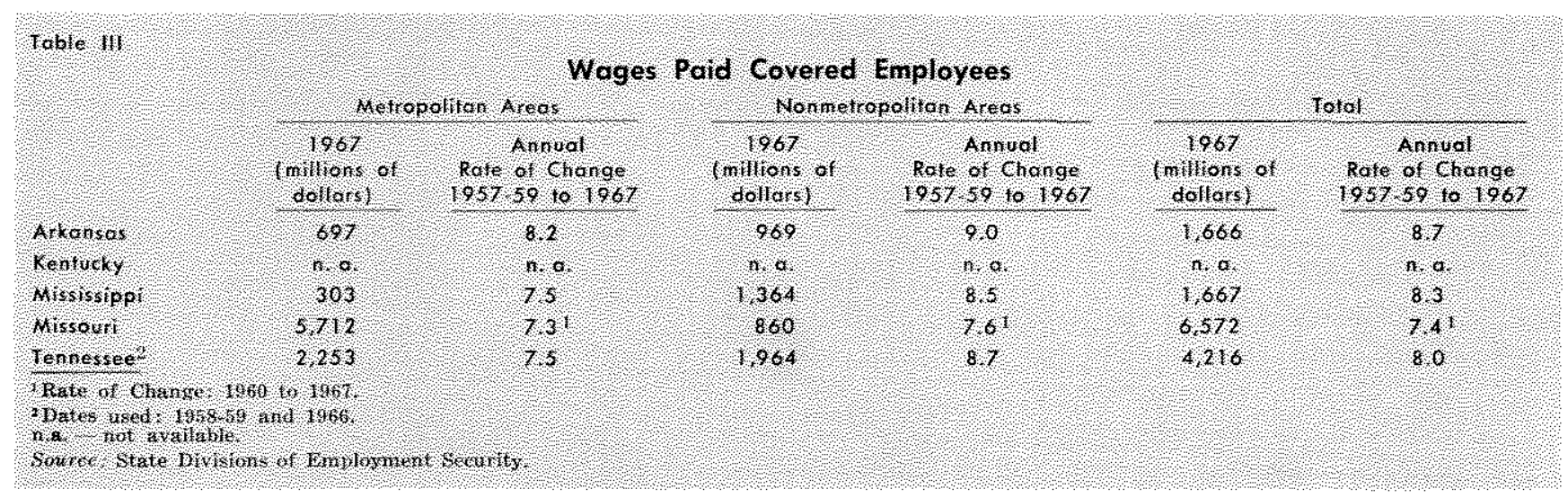

ment growth in nonmetropolitan areas has accelerated sharply. Total covered employment data are not available for Kentucky.

Covered employment in Mississippi expanded slightly faster in the nonmetropolitan sector than in the metropolitan sector during the period 1957-59 to 1967. During the first half of the 1960 's, nonmetropolitan growth was substantially more rapid, but the gap narrowed somewhat during the last two years. Growth rates for metropolitan and nonmetropolitan areas respectively, for the entire period, averaged 3.4 and 3,8 per cent per year.

Covered employment in Missouri has expanded slightly faster in nonmetropolitan areas than in the large centers. The faster growth of nonmanufacturing employment outside metropolitan areas was not offset by greater growth of manufacturing employment in metropolitan centers.

Covered employment figures for Tennessee indicate that nonmetropolitan employment has expanded considerably faster than metropolitan employment. During the 1950's employment in metropolitan areas grew more rapidly, but since 1960 the pattern has reversed, Growth rates for the 1958-59 to 1966 period are 5.2 per cent per year for nonmetropolitan areas and 3,6 per cent for metropolitan areas.

\section{Total Wages Paid}

Wages paid to covered employees have expanded faster in the nonmetropolitan areas of the Valley states than in metropolitan centers. Like the employment data, the wage figures apply to only about half of the employment in each state. They are, however, probably indicative of total wages paid in both sectors, exclusive of farm workers. The pattern of growth in total wages paid is similar to that of employment. Gains in the southern states were slightly faster than in Missouri, and gains in nonmetropolitan areas of each state were greater than in the metropolitan areas. Covered wage data are not avalable for Kentucky.

Arkansas, with the fastest total wage growth (8.7 per cent), also had the most rapid growth in the nonmetropolitan sector (Table IIr). Wages in metropolitan and nonmetropolitan Arkansas expanded at about the same rate from 1957-59 to 1965 , bui since 1965 they have accelerated in nonmetropolitan areas while leveling off in metropolitan centers.

Total wages advanced faster in nonmetropolitan than in metropolitan Mississippi from 1957-59 to 1967 , while the annual rates of increase in both sectors, 8.5 and 7.5 per cent, respectively, were very high. In the early part of the period the rate of expansion was about the same in the two sectors, but in recent years nonmetropolitan growth accelerated sharply. Wage growth in metropolitan Missouri approached that in the nonmetropolitan areas. Nonmetropolitan growth was more rapid from 1961 to 1965 , but metropolitan growth accelerated during the past two years. This pattern closely parallels the state's employment trends. Tennessee had a rather wide disparity in growth rates between the two sectors, with nonmetropolitan areas expanding faster. Wages in nonmetropolitan areas rose at an 8.7 per cent rate compared with 7.5 per cent in metropolitan areas. As in the case of employment, wages in metropolitan areas expanded more rapidly during the 1950 's, while nonmetropolitan wages have grown faster since 1960 .

\section{Bank noposis}

Bank deposits in the CMV states have followed the same pattern as other growth measures, rising faster in nonmetropolitan than in metropolitan areas and faster in the southern states where the population 


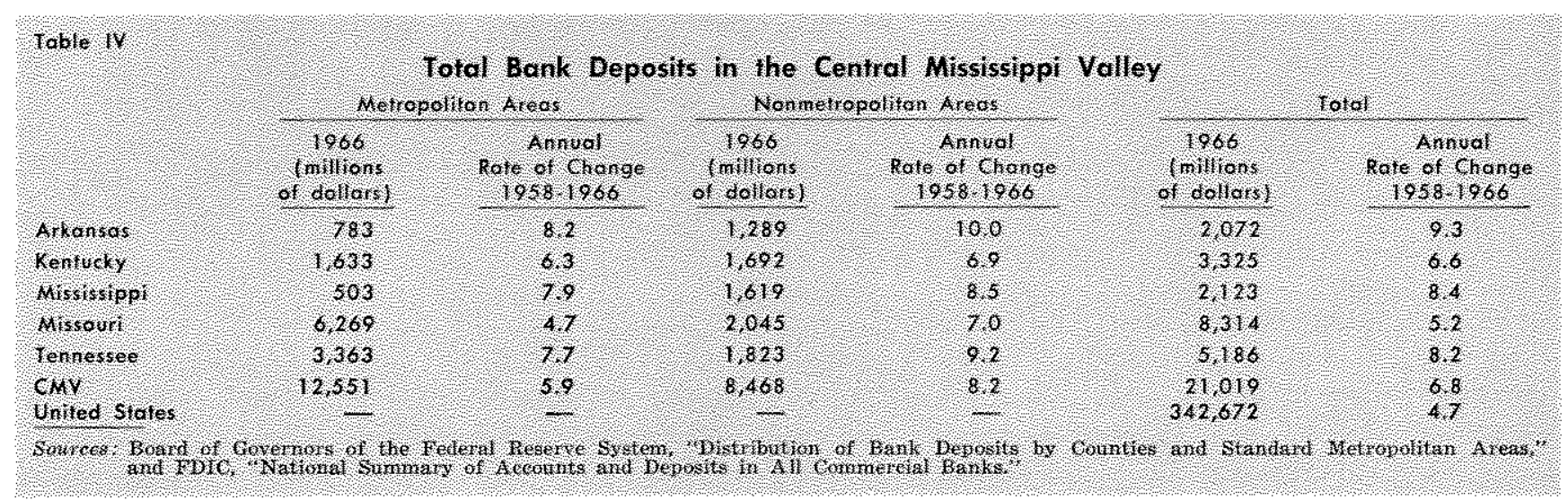

shifts have been greatest. Deposits rose at higher rates in each state from 1958 to 1966 than in the nation.

Arkansas had the greatest rate of deposit growth of the CMV states. With gains of 9.3 per cent per year, deposits in this state rose almost 50 per cent faster than the average for all CMV states and about double the national average (Table IV). Nonmetropolitan area deposits in Arkansas rose 10 per cent per year, compared with a 9.2 per cent rate in second place Tennessee, and an 8.2 per cent average for all nonmetropolizan areas in the CMV. The rate of deposit growth in Kentucky, although somewhat less than in the above states, again showed nonmetropolitan gains slightly more rapid than in the large centers.

In Mississippi, total deposits rose a little more rapidly in nonmetropolitan areas than in metropolitan centers. In both sectors, growth was relatively high, above the average for all Valley states, and total deposit growth greatly exceeded that in the nation.

Although bank deposits expanded less rapidly in Missouri than in other regional states, total and demand deposits each expanded faster in nonmetropolitan than in metropolitan areas. Demand deposits per capita expanded sharply in nonmetropolitan areas, whereas in metropolitan areas they declined slightly. This may reflect more intensive competition for savings-type deposits in metropolitan Missouri than in the nonmetropolitan areas. Rates paid on savings-type deposits average somewhat higher in metropolitan St. Louis than in outlying Missouri. Furthermore, opportunities for saving at nonbank financial agencies are more numerous in the St. Louis area than in most nonmetropolitan counties.

Deposit trends in Tennessee were very similar to those in the other Valley states, with total deposit growth more rapid in nonmetropolitan areas, particularly since 1962.

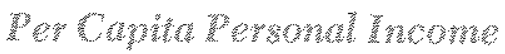

Per capita incomes made sharp gains in the nonmetropolitan areas of the CMV states from 1957-59 to 1966. A portion of the increase, especially during 1965 and 1966, reflected rising prices, but the rate after allowance for price increases was sizable. Like other growth factors, the rate of increase in the nonmetropolitan areas of each state was well above that

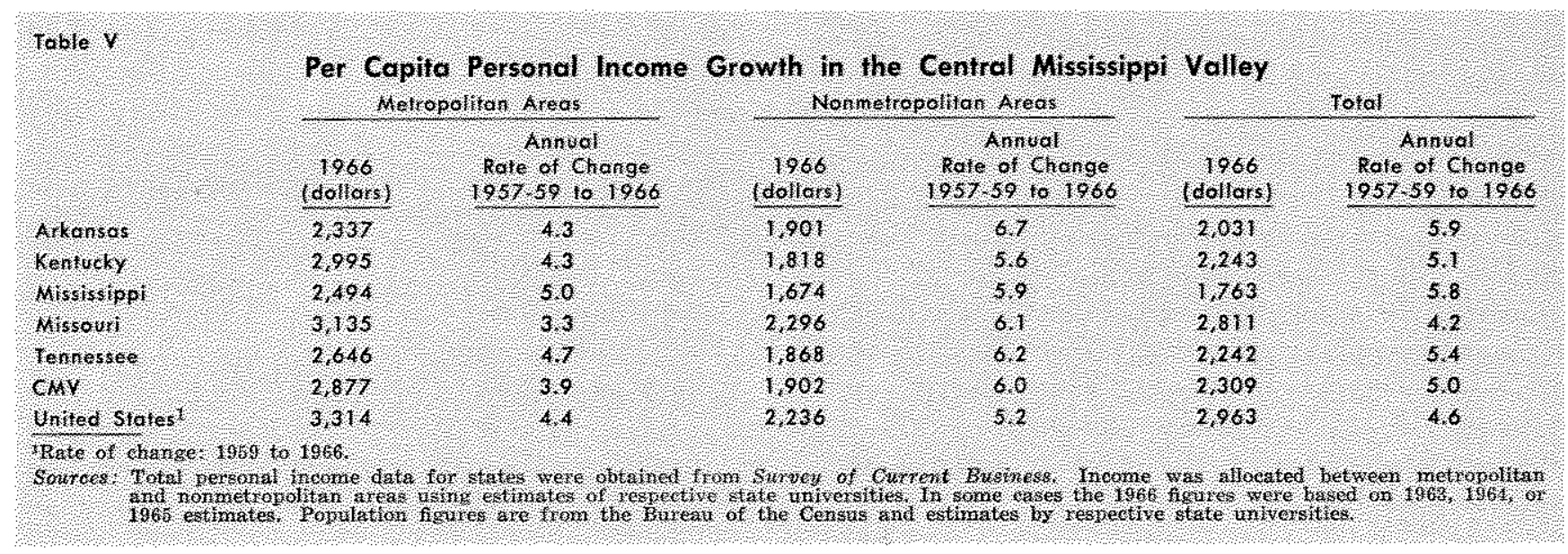


in metropolitan areas. Furthermore, per capita income gains in all regional states except Missouri were above the national average (Table $V$ ). Average per capita income growth in the Valley metropolitan areas trailed that of the nation's metropolitan areas.

With the rapid nommetropolitan gains in the Central Mississippi Valley, the per capita income sprend between metropolitan and nonmetropolitan areas narrowed substantially from 1957.59 to 1966 . At the earlier date, nonmetropolitan income averaged only 56 per cent of the metropolitan average, whereas in 1966 nommetropolitan income was about two-thirds that in metropolitan areas. The earlier spread between metropolitan and nonmetropoltan incomes in the Valley was much greater than that in the nation. By 1966, however, there was little difference in the spreads between the Valley and the nation.

Arkansas, which made the greatest labor adjustments from farm to nonfarm occupations, likewise had the highest rate of increase in nonmetropolitan per capita income and in the state average. By comparison, Arkansas metropolitan income per person rose only 4.3 per cent per year, slightly below the United States rate of gain, but above the Valley metropolitan average. Per capita income in nonmetropoli-

tan Arkansas rose from 68 to 81 per cent of the metropolitan average during this period.

Kentucky, with a somewhat lower rate of adjustment in farm labor than Arkansas, experienced a slower rate of per capita income growth in the nonmetropolitan areas. Nonmetropolitan per capita income growth in Kentucky was above the national average but below the Valley average, while metropolitan income growth was above the Valley average and almost equal the national average.

Mississippi ranked next to Arkansas in per capita income growth, reflecting growth in metropolitan areas greater than the Valley average, and about average growth in nonmetropolitan areas. Growth in nonmetropolitan Mississippi was still greater than in the large centers. Metropolitan areas grew faster in both income per capita and population than in other Valley states, indicating a strong demand for labor in the large centers. Despite this high growth rate, the state still ranks relatively low in per apita income, having achieved 60 per cent of the national average and 75 per cent of the Valley average. It also has a larger per cent of labor employed in agriculture than the Valley or national average.

Missouri had the lowest rate of per capita income growth of the Valley states, reflecting below average growth in the metropolitan sector. The state's nonmetropolitan per capita income rose somewhat faster than the Valley average, but this sector comprises only one third of the state's work force. Despite the slower rate of per capita income growth, incomes in Missouri are well above those of any other Valley state and almost equal the national average.

Per capita income growth and growth in each sector in Tennessee was slightly above average for the Valley. Furthermore, growth in nonmetropolitan areas of the state was above that in metropolitan areas. Here again, however, per capita incomes are well below the average in the valley states and the nation.

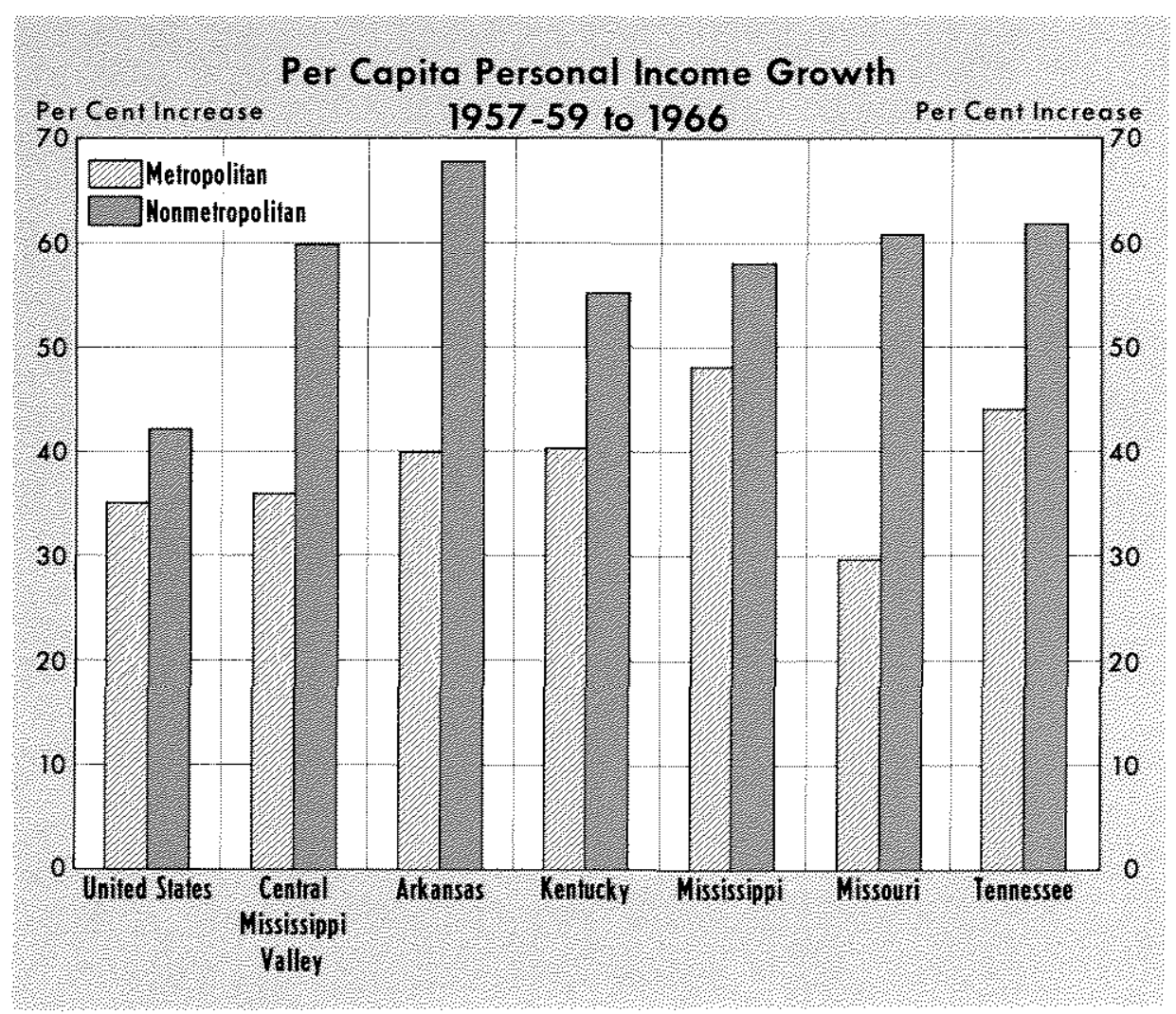




\section{Sมmman}

This section concludes that the fastest growing areas in the Central Mississippi Valley are the small cities, towns and urban-type communities outside the metropolitan counties. Measured in terms of population, employment, wages, bank deposits, and per capita personal income, growth rates in these areas exceeded those in metropolitan areas. Furthermore, despite the rapid decline in the farm population and the relatively low incomes in agriculture, bank deposits and per capita personal income grew faster in the entire nonmetropolitan sector of the Central Mississippi Valley than in the metropolitan areas.

\section{Routes to Growth}

Like most explanations for growth, an explanation of the rapid growth in nommetropolitan Central Mississippi Valley is complex. Major programs have focused on growth in metropolitan areas in recent years. Large Federal programs, designed to improve the labor force and increase employment, have been directed toward these centers. Most corporate headquarters are located there. Furthermore, the large centers have well-organized Chambers of Commerce and other resource and development groups designed to lure industry into their respective localities. Despite these efforts, however, growth in covered employw ment and per capita income has been more rapid outside the large centers.

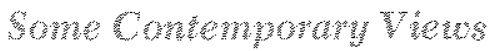

W. W. Rostow traces the growth pattern of nations through five stages, beginning with traditional societies that have a high proportion of resources in agriculture and a relatively inflexible social organization. ${ }^{4}$ $\mathrm{He}$ contends that as a prelude to moving forward, society must recognize that progress is possible and desirable. Also, some enterprising men are necessary. The government must be capable of organizing the nation so that unified commercial maxkets develop and lead the way in such areas as education, tariffs, and public health. The take-off which follows is characterized by a high rate of saving and capital investment, rapid expansion of new industries, and numerous new techniques for production in agriculture and industry. As the economy approaches maturity, it experiences long intervals of fluctuating progress.

4W. W. Rostow, The Stages of Economic Growth, (New York: Cambridge University Press, 1960), pp. 4-16.
About 60 years following take-off, as the economy demonstrates a capacity to move beyond the original industries which generated the take-off, the developing nation reaches a level of relative maturity. It is now at the age of mass consumption where emphasis shifts to durable goods and services.

Such analyses tell little about how the engine of progress is started. For example, how does a society develop entrepreneurs, and how does one reorient a society from the inflexible, structural type composed of relatively self-sufficient units to a flexible one built around commercial exchange and specialization of labor?

Rostow believes that the original impetus occurs in agriculture. 5 More food must be produced per worker to provide for those moving into urban areas and for the over-all rise in population. In addition, agriculture must supply expanded markets and loanable funds to the modem sector. Important ingredients for takeoff are willing entrepreneurs and improved markets for both factors of production and end products.

Theodore W. Schultz has advanced the hypothesis that economic development in regions of the United States occurs in a specific location matrix, primarily urban, and that it works best in those parts of agticulture nearest to the center of the matrix. "He traced low incomes in agriculture to inefficient factor markets. An implication of the study is that both farm labor and capital are relatively immobile.

D. Gale Johnson has also suggested that we have had inefficient functioning of the labor market. ${ }^{7}$ He indicated that the failure of migration to achieve equality of returns in the farm and nonfarm sectors rests largely on influences indigenous to farm people and their environment.

\section{Inwrovenens in the Labor and

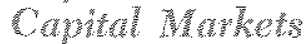

Despite these pessimistic conclusions, labor and capital markets in the Central Mississippi Valley have apparently functioned more efficiently in recent years. The income gap between metropolitan and smaller centers has closed substantially. Furthermore, re-

\footnotetext{
5Rostow, p. 22.

6Theodore W. Schultz "A Framework for Land Economics - The Long View," Journal of Farm Economics, July 1951, pp. $205-206$.

TD. Gale Johnson, "Functioning of the Labor Market" Jounnal of Farm Economics, February 1951, p. 87.
} 
source adjustments and per capita income gains have been greatest in Arkansas and Mississippi, where a larger percentage of the resources were farmoriented and the metropolitan areas were relatively small. The data thus suggest that since 1950 capital and labor markets have been working more efficiently throughout the Valley, and that efficient factor markets are not limited to the periphery of large metropolitan centers. The study indicates sharp movements of capital into nonmetropolitan communities, and of labor out of agriculture. Some incentive apparently remains for labor to move to metropolitan areas, but in the Valley states this incentive, based on per capita personal income, has declined since the early 1950's.

Although per capita income is usually considered one of the best measures of economic well-being in an area, it is far from perfect. In the first place, it is not adjusted for differences in living costs which may be quite substantial among urban areas, between urban and rural areas, or among rural areas. Some expenses, such as parking fees, cost of travel to and from work, and clothing, are inconsequential for most farm workers. Food and housing costs may also be lower. Part of the difference in average per capita incomes between metropolitan and nonmetropolitan areas may be an indication of unequal labor and managerial skills. For example, according to the 1960 Census of Population, the median school years completed by urban residents of the South was 10.7, while the median for rural nonfarm and rural farm residents, respectively, was 8.9 and 8.4 years. The per cent of those residents with college degrees similarly indicates an educational gap between metropolitan and nonmetropolitan areas.

In addition, the personal income data do not measure capital gains, which may be greater relative to income in the nonmetropolitan sector than in metropolitan areas. Many farmers, for example, obtain sizable capital gains because they are landowners. In 1964 more than four-fifths of all farm operators were simultaneously landowners, according to the United States Census of Agriculture. Gains to landowners from rising land prices have been pointed out by numerous studies. ${ }^{8}$ William Diehl found that capital gains in agriculture were a significant deterrent to migration." He thus implied that capital gains in farming are associated with the size of the farm labor force, given the current structure of agriculture. D. Gale Johnson estimated that due to sizable nonmonetary gains in agriculture, farm incomes equal to 68 per cent of nonfarm incomes provide the same real return to labor in the two sectors, ${ }^{10}$

It is apparent from these studies that equality of money incomes in the metropolitan and nonmetropolitan sectors is not essential for equality of real incomes. How close the sectors are to equality is a question that remains unanswered. Nevertheless, the fact that population (excluding farm residents) and covered employment have grown faster outside of metropolitan areas than in large centers indicates that such areas are relatively more desirable places to work and live than in former years when metropolitan centers were growing at more rapid rates relative to smaller communities.

\section{Conclusion}

From 1950 to 1966 marked population shifts occurred in five states of the CMV, with smaller cities and towns growing rapidly. Farm population declined markedly. Metropolitan counties in the CMV states grew at a 1.7 per cent annual rate, and the nonfarm population outside of metropolitan areas at a 2.8 per cent rate. The number of people remaining on farms is now so small that further mass migration out of agriculture can no longer occur. This situation will tend to reduce the future rate of growth both of metropolitan areas and of nonfarm nonmetropolitan areas in the CMV.

8See Mason Gaffney, "The Benefits of Farm Programs: Incidence, Shifting and Dissipation," Journal of Farm Economics, December 1965, pp. $1252-1264$ and Walter E. Chryst, "Land Values and Agricultural Income," Journal of Farm Economics, December 1965, pp. 1265-1273.

"William D. Diehl, "Farm-Nonfarm Migration in the Southeast: A Costs-Returns Analysis," Journal of Farm Economics, February 1966, op. 1-11.

10D. Gale Johnson, "Labor Mobility and Agricultural Adjustment," Agricultural Aditutment Problems in a Growing Economy, (Ames, lowa: lowa State University Press, 1956), p. 164 .

Glifton B. LutTrele

Clatre Armentrout 